
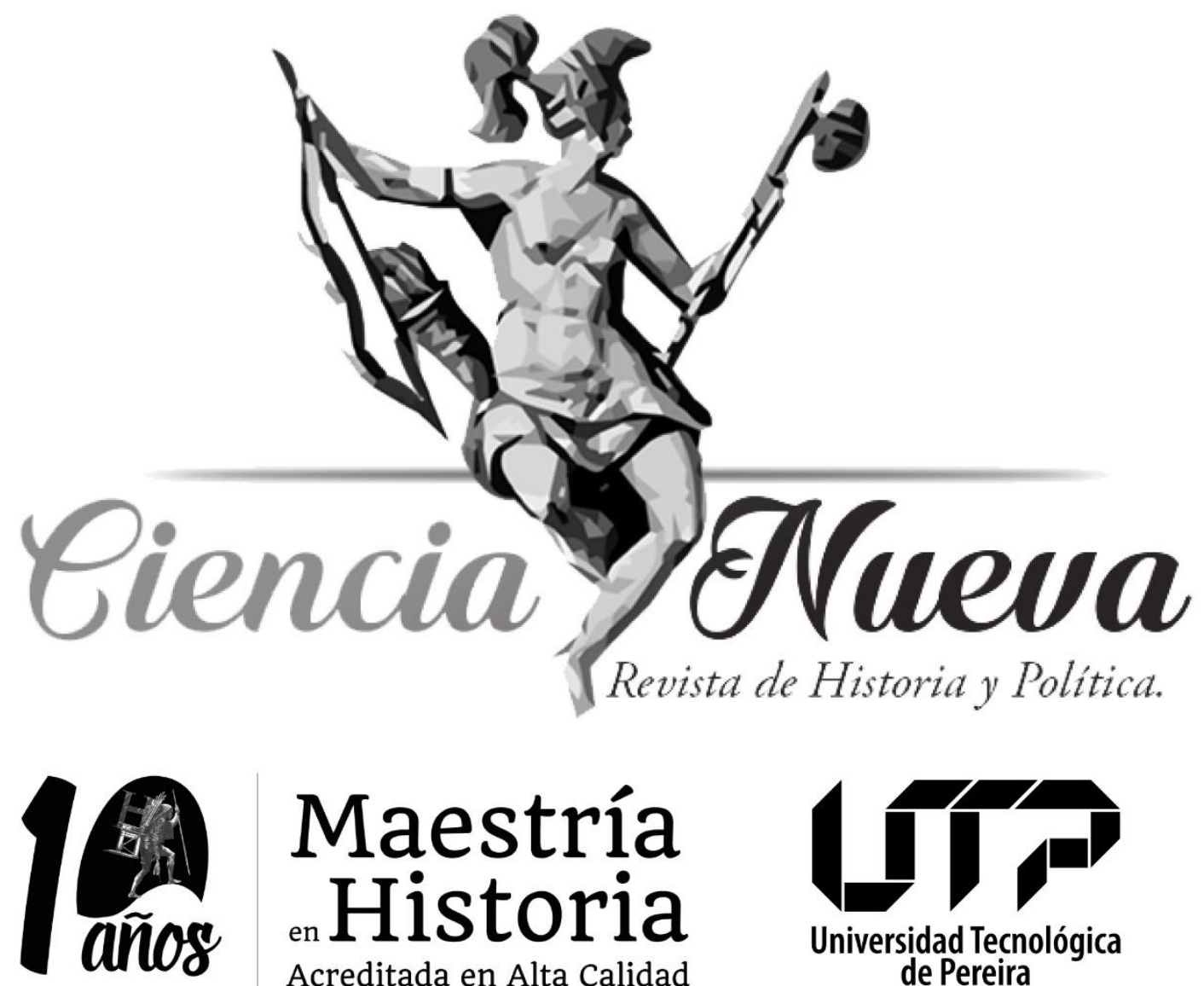

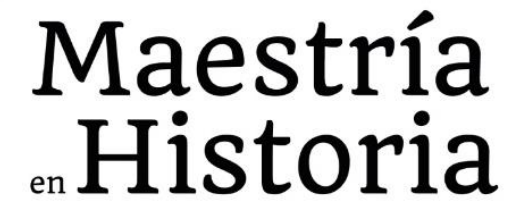

Acreditada en Alta Calidad

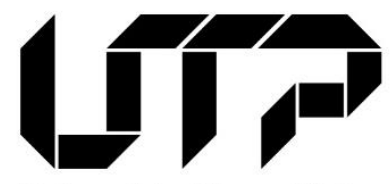

Universidad Tecnológica de Pereira

RESEÑAS

AMAYA, JAVIER. SANTIAGO LONDOÑO LONDOÑO, EL HOMBRE Y LA LEYENDA. PEREIRA: GRÁFICAS BUDA; SEATTLE: EDICIONES LA CIGARRA, 2020 AMAYA, JAVIER. SANTIAGO LONDOÑO LONDOÑO, THE MAN AND THE LEGEND. PEREIRA: GRÁFICAS BUDA; SEATTLE: EDICIONES LA CIGARRA, 2020

Gustavo Álvarez Gardeazábal pp. 206-208

DOI: https://doi.org/10.22517/25392662.24634

Vol. 4 Núm. 2 | Julio-diciembre de 2020

Pereira, Colombia

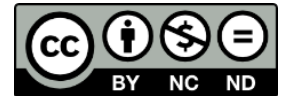




\title{
Amaya, Javier. Santiago Londoño Londoño, el hombre y la leyenda. Pereira: Gráficas BUdA; SEATtLe: Ediciones La Cigarra, 2020 *
}

\author{
Amaya, Javier. Santiago Londoño Londoño, the man AND THE LEgend. Pereira: \\ Gráficas Buda; Seattle: Ediciones la Cigarra, 2020 **
}

\author{
Gustavo Álvarez Gardeazábal ${ }^{* * *}$
}

\begin{aligned} & \hline Recibido: 19 de septiembre de 2020. \\ & Aceptado: 21 de diciembre de 2020. \\ & Publicado: 31 de diciembre de 2020. \\ & \hline\end{aligned}

En Pereira nació hace 100 años Santiago Londoño Londoño. Fue médico oncólogo, piloto de avión, cultivador de café, concejal y diputado, homosexual confeso, mecenas de las artes y miembro activo del Partido Comunista Colombiano, a quien le dejó por testamento su cuantiosa herencia. Su vida generó tantos efectos sociales, políticos y de salubridad pública, que su recuerdo ha quedado imborrable en el Eje Cafetero y generado siempre, en vida y muerte, un respeto por sus ideas y una admiración por su generosidad. Como lo repite el escritor Javier Amaya en su obra Santiago Londoño Londoño, el hombre y la leyenda, hasta Luis Carlos González, el poeta de la ruana, le dedicó un poema que termina «en el surco sembrado de sus nobles favores / crece el trigo silente de los gratos deudores / que le pagan la vida pronunciando su nombre».

Hombre singular este pereirano porque no debió haber sido fácil combinar su riqueza económica con su militancia en el Partido Comunista, ya que entendió que lo único que perdura en un pueblo andino es el arte de sus gentes y no el cansancio que deja el exceso de trabajo. Pero en especial, porque desde donde viera el mundo que lo rodeaba pudo encontrar siempre cómo ayudar a sus amigos, a su ciudad y a su Partido Comunista.

La biografía que en ocasión de su centenario ha publicado inicialmente en Seattle el risaraldense Javier Amaya y ahora lo hace la Universidad Tecnológica de Pereira, es más una visión de conjunto sobre elementos mínimos de su huella que una explicación de la extraña habilidad de ese hombre para conjugar la generosidad con la valentía, el atrevimiento con la independencia y la firmeza de carácter con la bondad de espíritu. Quizás por ello tuvo el mismo ímpetu para montarse en su avioneta e ir a las playas del Pacífico a desperdigar sus ayudas sin temer a las cúspides del Tatamá ni a los soldados y policías de Turbay, o a las tempestades chocoanas, o para ir por las carreteras del Valle en su veloz motocicleta de alto cilindraje, en la cual finalmente encontró la muerte estrellándose contra un árbol a gran velocidad en inmediaciones de Zarzal en agosto de 1982, y que sirve inútilmente al biógrafo para expandir una teoría conspiracionista sobre las reales razones de su accidente.

\footnotetext{
* Esta reseña fue publicada originalmente por el autor en su canal de Youtube con el título CRÓNICA DE UN ENCHUSPADO \# 113, Santiago Londoño, el 11 de julio de 2020. Ciencia Nueva reproduce esta transcripción con autorización del autor.

${ }^{* *}$ Este documento respeta las directrices y normas dispuestas en la Declaración de Ética de Publicación de Ciencia Nueva, Revista de Historia y Política. Esta declaración puede consultarse en la página web de la revista: http://revistas.utp.edu.co/index.php/historia

${ }^{* * *}$ Escritor, crítico literario, periodista y político oriundo de Tuluá, Valle del Cauca. Doctor honoris causa en Literatura de la Universidad del Valle.
} 
Pereira le rinde permanente homenaje habiendo construido y bautizado el Teatro Municipal con su nombre, en el lote que él donara en vida para ese propósito. En cambio, el Partido Comunista no ha sido tan grato con su gran mecenas, a quien el camarada Gómez me presentara fugazmente en la tarde que firmé ejemplares de Cóndores no entierran todos los días en su chacrita del Parque Bolívar de Pereira, hace tantos años, donde a más de la Voz Proletaria el viejo vendía la edición popular que hizo Ariel de Guayaquil de mi libro y se enorgullecía de tener como su cliente y su jefe político a ese señorón que luego de despedirse cordialmente, lo vi montarse en un lujoso Mercedes negro a seguir siendo el inolvidable Santiago Londoño, el comunista, el médico, honra y prez de Pereira.

El Porce, julio 11 de 2020. 